\title{
ESPOROS E FRUTIFICAÇÕES DE FUNGOS HOLOCÊNICOS DE TESTEMUNHO DA LAGOA DA FERRADURA (ARMAÇÃO DOS BÚZIOS, RIO DE JANEIRO, BRASIL)
}

\author{
ALINE GONÇALVES DE FREITAS \& MARCELO DE ARAUJO CARVALHO \\ Laboratório de Paleoecologia Vegetal, Departamento de Geologia e Paleontologia, Museu Nacional/UFRJ, \\ Rio de Janeiro, 20940-040, RJ, Brasil.tuttyfreitas@gmail.com,mcarvalho@mn.ufrj.br
}

\begin{abstract}
HOLOCENE FUNGAL SPORES AND FRUTIFICATIONS OF A CORE FROM THE FERRADURA LAGOON (ARMAÇÃO DOS BÚZIOS, RJ, BRASIL). Fungal spores and frutifications suggest environmental changes on Armação dos Búzios Peninsula (Lakes Region, Rio de Janeiro State, SE Brazil) before 7,880 years BP to current days. Holocene sediments of Ferradura Lagoon were processed by Quaternary palinological method, what made possible recovery abundant and diversified microfungi. In this study were identified 21 genera of fungal spores Deuteromycetes: Amerosporae (7), Didymosporae (4), Phragmosporae (6), Dictyosporae (1), Staurosporae (3); and one genus of frutification: Ascomycetes (Callimothallus). The identified genera were morphologically compared with modern living microfungi, which may reflect ecological interactions with certain groups of plants, such as Frasnacritetrus and grasses, Reduviasporonites/Aspergillus and Pteridophytes, and Dictyosporites/Arbuscula on Eugenia sp. (Myrtaceae) leaves, barks of some deciduous trees, and even some species of Rhamnaceae. The majority of the identified microfungi on RJ 92-5 core suggest a coastal environment with brackish waters from mangroves, moist soils and warm climate. These results agree with the Holocene paleoenvironmental characterization of eastern portion of Armação dos Búzios Peninsula based on pollen data.
\end{abstract}

Key words: fungal spores, frutifications, paleoenvironment, Holocene, Ferradura Lagoon, Búzios.

RESUMO - Os esporos e frutificações de fungos sugerem mudanças ambientais ocorridas na península de Armação dos Búzios (Região dos Lagos, Rio de Janeiro) desde antes de 7.880 anos AP até os dias atuais. Os sedimentos holocênicos da lagoa da Ferradura foram processados pelo método palinológico para o Quaternário, possibilitando abundante e diversificada recuperação de microfungos. Neste estudo recuperação foram identificados 21 gêneros de esporos de fungos Deuteromycetes: Amerosporae (7), Didymosporae (4), Phragmosporae (6), Dictyosporae (1), Staurosporae (3); e um gênero de frutificação: Ascomycetes (Callimothallus). A comparação entre microfungos holocênicos e recentes permitiu a reconstrução de aspectos da vegetação local. Por exemplo, Frasnacritetrus interage com gramíneas, Reduviasporonites/Aspergillus com pteridófitas e Dictyosporites/Arbuscula se encontra em folhas de Eugenia sp. (Myrtaceae), em troncos de árvores decíduas e, também, em algumas espécies de Rhamnaceae. A maioria dos microfungos identificados aponta ambiente costeiro com influência de águas salobras de manguezais, solos úmidos e clima quente. Estes resultados corroboram análises polínicas utilizadas na caracterização paleoambiental da porção leste da península de Armação dos Búzios durante o Holoceno.

Palavras-chave: esporos de fungos, frutificações, paleoambiente, Holoceno, lagoa da Ferradura, Búzios.

\section{INTRODUÇÃO}

Registros palinológicos abrangem praticamente todos os reinos dos seres vivos: Animalia, Plantae, Protista e Fungi. No entanto, tradicionalmente os palinomorfos de origem vegetal e os protistas são os mais estudados.

De forma sistemática, os estudos de microfungos (i.e. esporos e frutificações) vêm crescendo ao longo dos anos, inclusive com destaque na utilização dos mesmos em reconstruções paleoambientais (Wolf, 1967; Kalgutkar \& Jansonius, 2000) e aplicação à indústria do petróleo (Kalgutkar \& Sigler, 1995). As descrições morfológicas dos esporos e frutificações de fungos, registradas em períodos geológicos anteriores ao
Quaternário, fornecem suporte para investigações palinoestratigráficas e paleoecológicas (Wolf, 1967; Ramanujam \& Rao, 1978; Ramanujam \& Srisailam, 1980; Jarsen \& Elsik, 1986; Kalgutkar \& McIntyre, 1991; Kalgutkar \& Sigler, 1995; Carvalho, 1996, 2003; Kalgutkar \& Jansonius, 2000; Ferreira et al., 2005). A correlação entre os microfungos fósseis e recentes torna-se importante para a determinação de paleoambientes (Lange \& Smith, 1971; Ramanujam \& Rao, 1978; Ramanujam \& Srisailam, 1980; Jarzen \& Elsik, 1986; Pirozynski et al., 1988; Kalgutkar \& McIntyre, 1991), além de corroborar análises polínicas na interpretação das mudanças da vegetação e sucessões florísticas de épocas passadas (Wolf 1967; Kaugtkar \& Jansonius, 2000). 
Os fungos são organismos unicelulares ou multicelulares, heterotróficos, não-fotossintetizantes de hábito epifítico, saprofítico, parasitas ou simbiontes com plantas e animais vivos ou mortos (Kalgutkar \& Jansonius, 2000). Esta diversidade ecológica faz com que este táxon tenha um grande potencial como indicador em reconstruções paleoambientais. Estes organismos, quando presentes em amostras palinológicas, podem fornecer informações adicionais sobre o ambiente local, como mudanças no regime hidrológico, condições tróficas, registro de queimadas e presença de excrementos animais (van Geel et al., 2003).

As análises palinológicas realizadas por van Geel (1978), em sedimentos de pântanos e lagos holocênicos, revelaram associações paleoecológicas entre esporos de fungos e outros palinomorfos não-polínicos. As relações entre os esporos do fungo parasita Ustulina deusta e táxons arbóreos foram assinaladas por van Geel \& Andersen (1988) em depósitos pleistocênicos da Dinamarca. Posteriormente, foram identificados fungos hiperparasitas (e.g. Meliola, Calluna, Isthymospora) em uma turfeira ombrotrófica no norte da Inglaterra, como provável influência de precipitação sazonal (van Geel et al., 2006). Nas investigações palinológicas de sedimentos plio-pleistocênicos da bacia da Foz do Amazonas, Carvalho $(1996,2003)$ observou uma abundância e diversidade de esporos de fungos associados a esporos de pteridófitas, grãos de pólen de floresta tropical e dinoflagelados. Esta associação prevaleceu em fases interglaciais indicando sedimentação subaquática em ambiente deltaico na bacia, com aumento das condições úmidas e proximidade dos sedimentos com a área-fonte. Em análises de sedimentos de talude da bacia de Campos, Freitas (2005) registrou a presença de esporos e frutificações de fungos terrestres. A deposição dos fungos em ambiente marinho distal provavelmente está relacionada ao rebaixamento relativo local do nível do mar, decorrente das glaciações pleistocênicas.

O presente trabalho consiste em realizar análises qualitativas e quantitativas dos restos de fungos e investigar suas associações ecológicas com os demais palinomorfos identificados no testemunho RJ 92-5 extraído da lagoa da Ferradura, Armação dos Búzios, Região dos Lagos, Rio de Janeiro. Os resultados contribuem para a caracterização paleoambiental da área estudada, durante o Holoceno.

\section{MATERIAL E MÉTODOS}

O testemunho RJ 92-5 (2248’45"S, 41 $\left.{ }^{\circ} 54^{\prime} 13^{\prime \prime W}\right)$ foi coletado por meio de vibro-testemunhador, em uma sondagem realizada na lagoa da Ferradura, Armação dos Búzios, Região dos Lagos, Rio de Janeiro (Figura 1). O testemunho possui 4,35 m de comprimento e seus sedimentos compreendem pacotes de argilas orgânicas com laminações

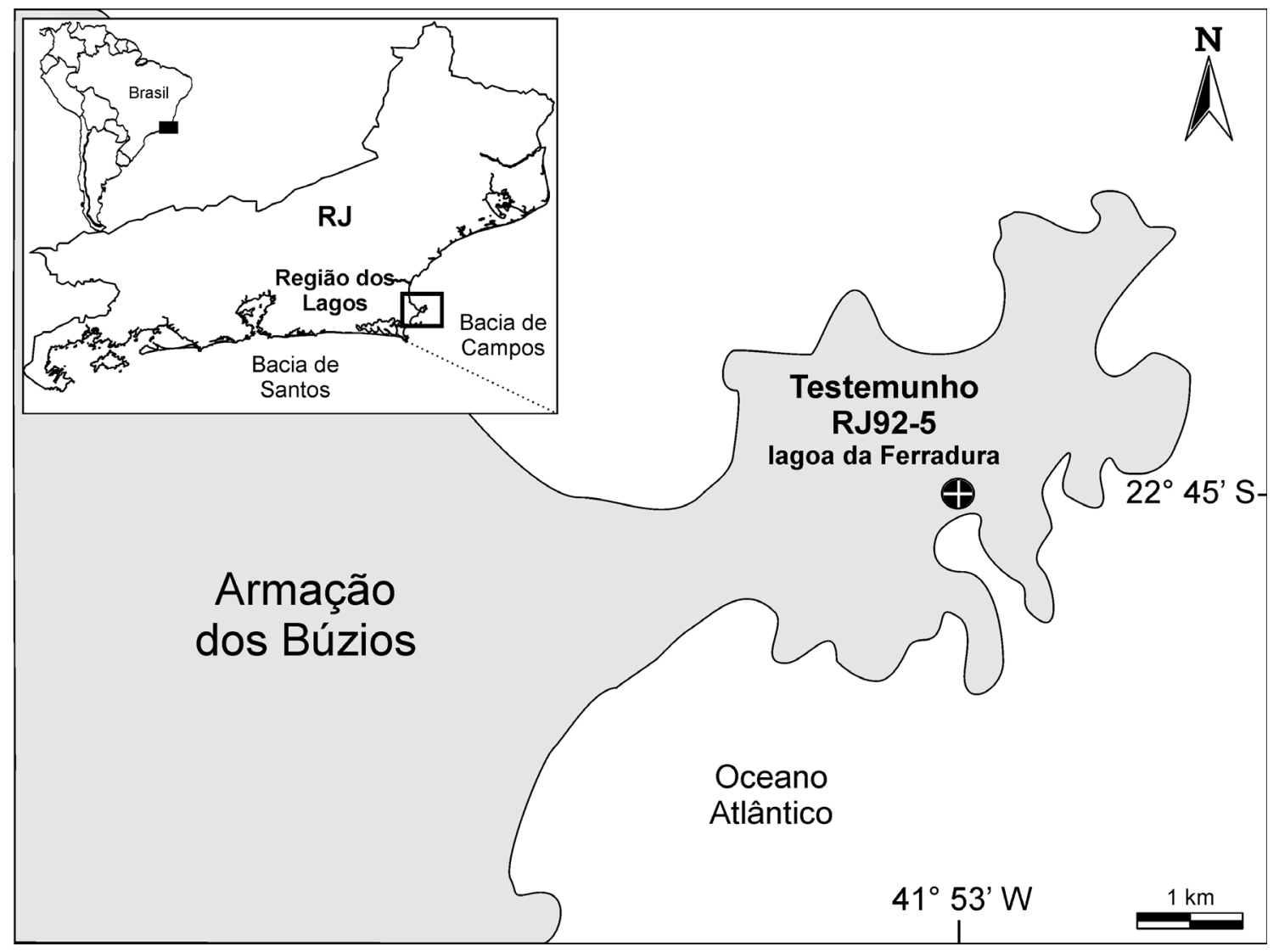

Figura 1. Mapa de localização do testemunho RJ 92-5.

Figure 1. Location map of core RJ 92-5. 
carbonáticas, depósitos carbonáticos a 270, 200 e $110 \mathrm{~cm}$, areia fina argilosa na base e argila arenosa nos níveis 100 e 80 cm (Figura 2). Foram analisadas 27 amostras (ca. 2-3 g cada), coletadas de 20 em $20 \mathrm{~cm}$ e tratadas pelo método padrão palinológico para o Quaternário que consiste em utilizar $\mathrm{HCl}$ a $10 \%$, HF $40 \%$, acetólise e introdução das pastilhas de Lycopodium clavatum para calcular as concentrações de palinomorfos (Ybert et al., 1992). As lâminas foram montadas com gelatina glicerinada e lutadas com parafina. O testemunho RJ 92-5 possui cinco datações radiocarbônicas AMS realizadas pelo laboratório Beta Analytic (Florida, USA): 100 +- 50 AP (90 anos cal AP) em $3 \mathrm{~cm} ; 3.690$ +- 40 AP (4.410 anos cal AP) em $60 \mathrm{~cm} ; 4.830$ +- 80 AP (5.590 anos cal AP) em 150,5 $\mathrm{cm} ; 4.910$ +- 80 AP (5.680 anos cal AP) em $170 \mathrm{~cm} ; 4.900$ +- 100 AP (5.690 anos cal AP) em $177 \mathrm{~cm} ; 7.090$ +- 100 AP (7.880 anos cal AP) em $342 \mathrm{~cm}$ (Figura 2). As idades foram calibradas de acordo com o programa CALIB Rev 5.0.1 (Stuiver \& Reimer, 1993). Para tais calibrações foi utilizada a curva de calibração IntCal04 com precisão de 2 sigma.

A identificação dos restos de fungos seguiu as publicações de Kalgutkar \& Jansonius (2000), Jansonius \& Kalgutkar (2000), Saccardo (1931) e van Geel (1978). Os fungos foram classificados em nível genérico, de acordo com a classificação de Saccardo (1931) e Elsik (1976). As descrições dos esporos e frutificações de fungos foram obtidas através de microscopia de luz transmitida, em aumentos de 400x e 1000x. As descrições morfológicas se fundamentaram nos caracteres propostos por Kalgutkar \& Jansonius (2000), que inclui o tamanho e a forma dos esporos, a septação, a ornamentação da parede, e a presença ou ausência, o número e a natureza das aberturas. Esses caracteres possibilitam uma comparação morfológica entre os fungos fósseis e os táxons moder- nos. Os restos de fungos (esporos e frutificações) fósseis identificados neste trabalho foram comparados com os morfotipos atuais descritos por Kalgutkar \& Jansonius (2000). As fotomicrografias dos microfungos foram obtidas em aumentos de 1000x (Figuras 3-5).

A contagem polínica incluiu em torno de 300 grãos de pólens terrestres. Os esporos e frutificações de fungos, assim como os outros palinomorfos foram contados separadamente. Os percentuais dos palinomorfos e grupos ecológicos destacados no diagrama correspondem aos maiores valores de cada intervalo palinológico (Figura 2). O diagrama palinológico foi gerado no programa C2 (Juggins, 2003). Os intervalos palinológicos, definidos pela análise estatística de agrupamento (Figura 2) foram gerados no programa PAST 2.04 (Hammer et al., 2001).

\section{RESULTADOS E DICUSSÃO}

\section{Composição taxonômica}

Foram encontrados e caracterizados morfologicamente (Tabela 1; Figuras 3-5) 20 gêneros de esporos de fungos pertencentes à Classe Deuteromycetes (Fungi Imperfecti): Grupo Amerosporae (Diporisporites, Foveodiporites, Hypoxylonites, Inapertisporites, Lacrimasporonites, Paleoamphisphaerella, Striadisporites), Grupo Didymosporae (Dicellaesporites, Fusiformisporites, Dyadosporites), Grupo Phragmosporae (Diporicellaesporites, Multicellaesporites, Pluricellaesporites, Quilonia, Reduviasporonites, Staphlosporonites), Grupo Dictyosporae (Dictyosporites), Grupo Staurosporae (Frasnacritetrus, Spegazzinites, Triporicellaesporites), e um gênero de frutificação de fungo representante da Classe Ascomycetes (Fungi Perfecti): Microthyriales (Callimothallus).

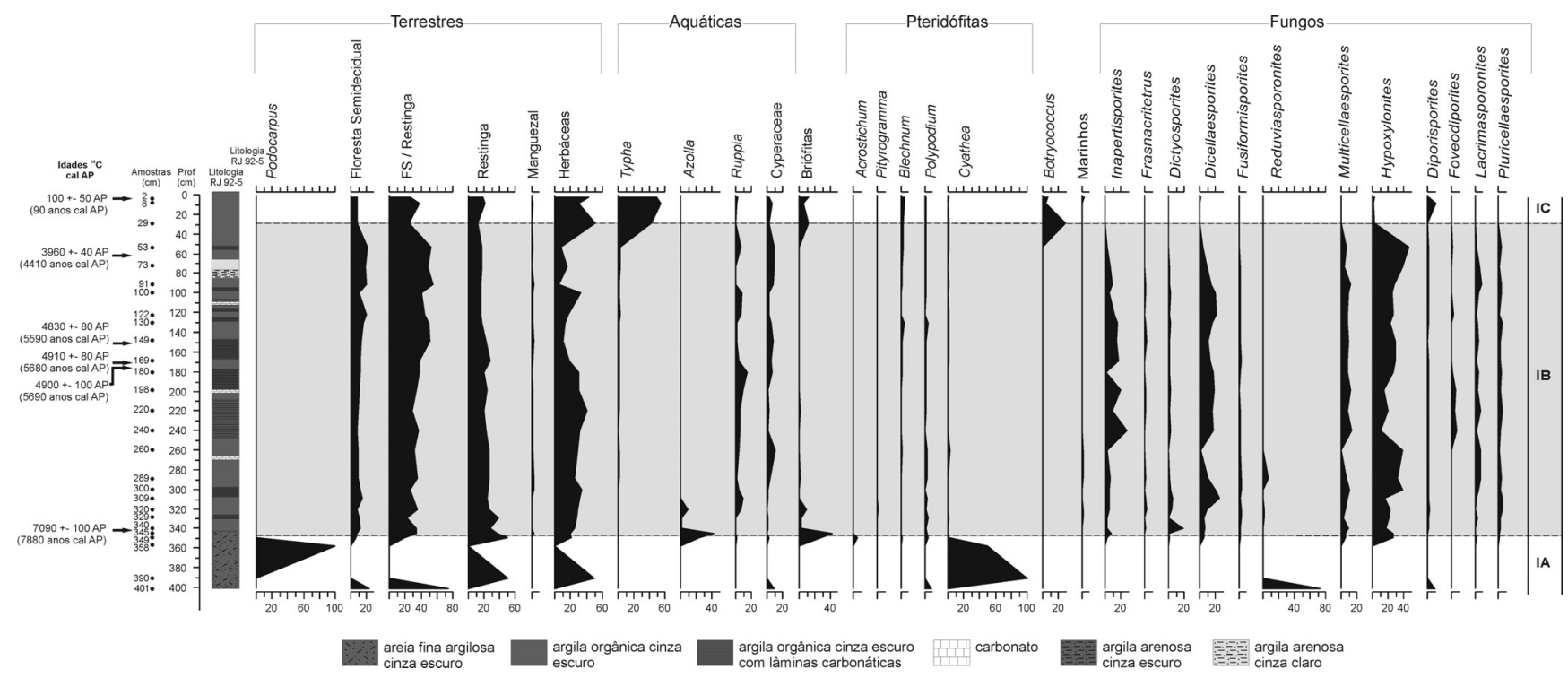

Figura 2. Diagrama palinológico com os principais grupos ecológicos e esporos e frutificações de fungos do testemunho RJ $92-5$, lagoa da Ferradura. A soma polínica exclui aquáticas, esporos de briófitas e pteridófitas, algas, fungos e elementos marinhos.

Figure 2. Palynological diagram with ecological groups and fungal spores and frutifications of core RJ 92-5, Ferradura Lagoon. The pollen sum excludes aquatics, fern and bryophyte spores, algae, fungal and marine elements. 


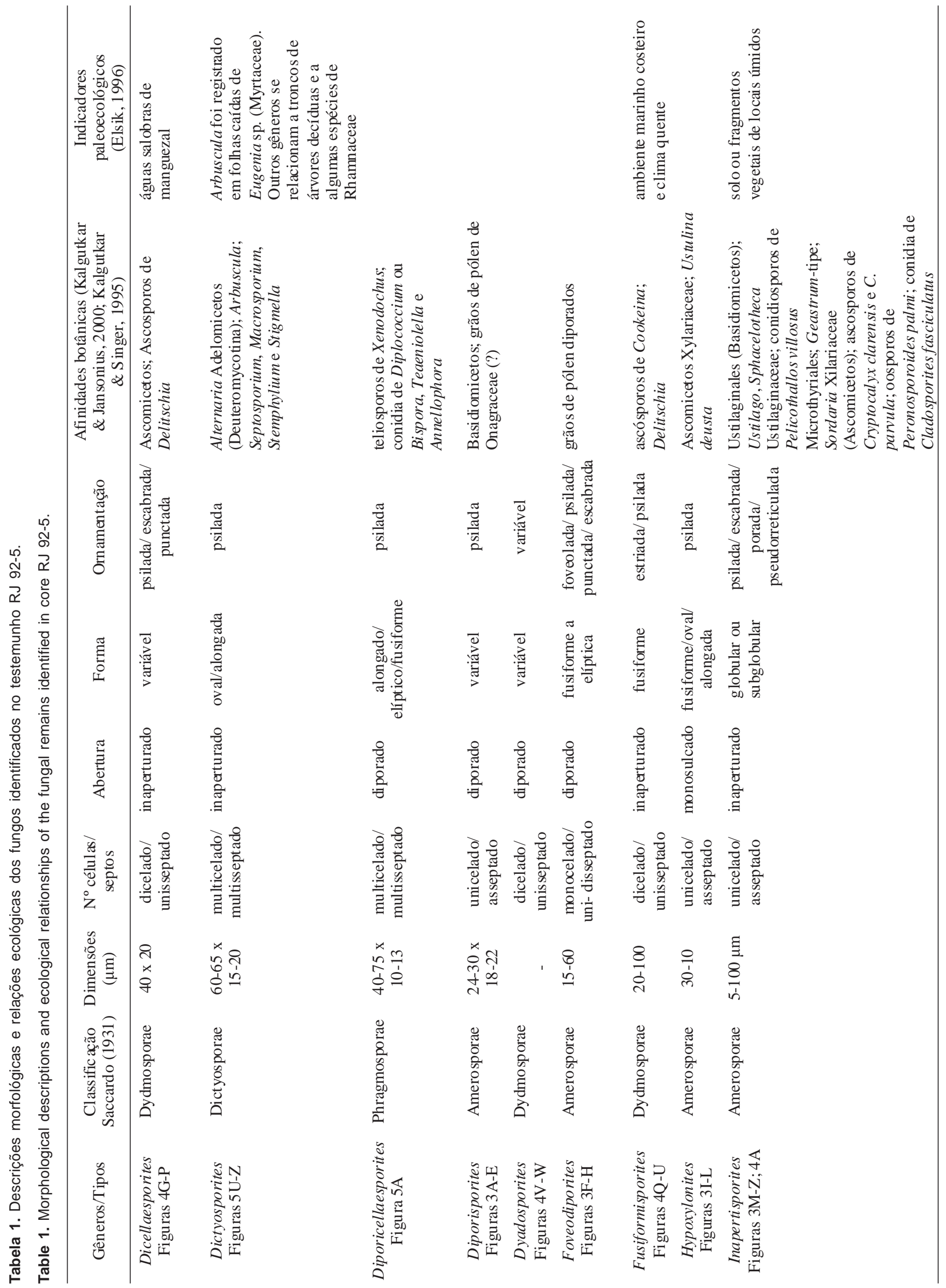




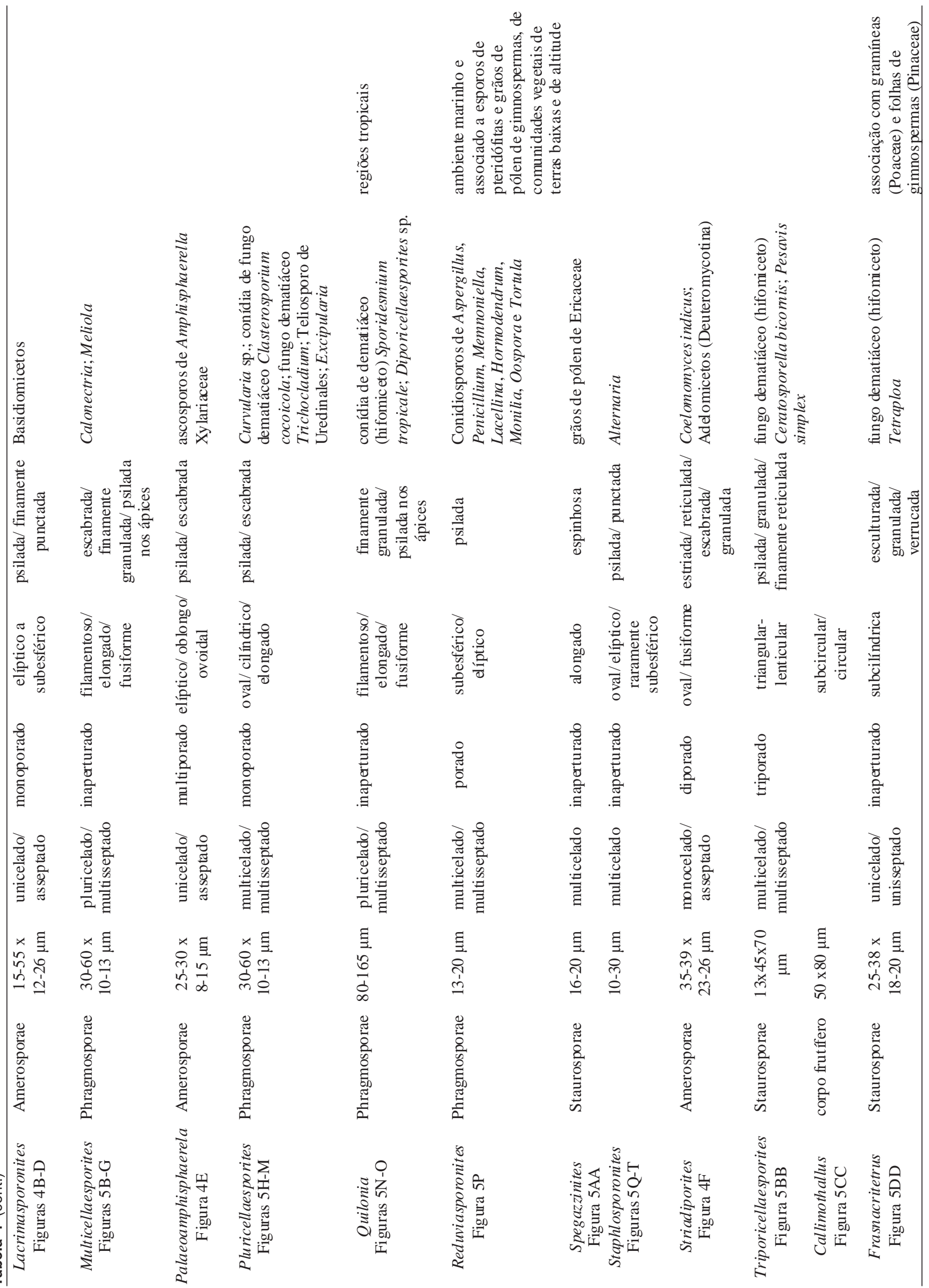




\section{Intervalos palinológicos}

A análise de agrupamento empregada permitiu dividir o testemunho em três intervalos com base na abundância dos principais grupos de palinomorfos, incluindo os esporos e frutificações de fungos (Figura 2), descritos da base para o topo do testemunho. Os esporos de fungos com percentuais mais significativos ao longo do testemunho RJ 92-5 foram:
Reduviasporonites (até 72,7\%), Hypoxylonites (46,5\%), Inapertisporites (28\%), Dictyosporites (19,1\%), Dicellaesporites (25,2\%), Multicellaesporites (13\%), Diporisporites $(9,7 \%)$ e Lacrimasporonites $(8,1 \%)$ (Figura 2$)$.

Intervalo IA (401-349 cm). Este intervalo é marcado pela presença abundante de esporos de fungos marinhos (Reduviasporonites até $72,7 \%$ ), além de esporos de fungos

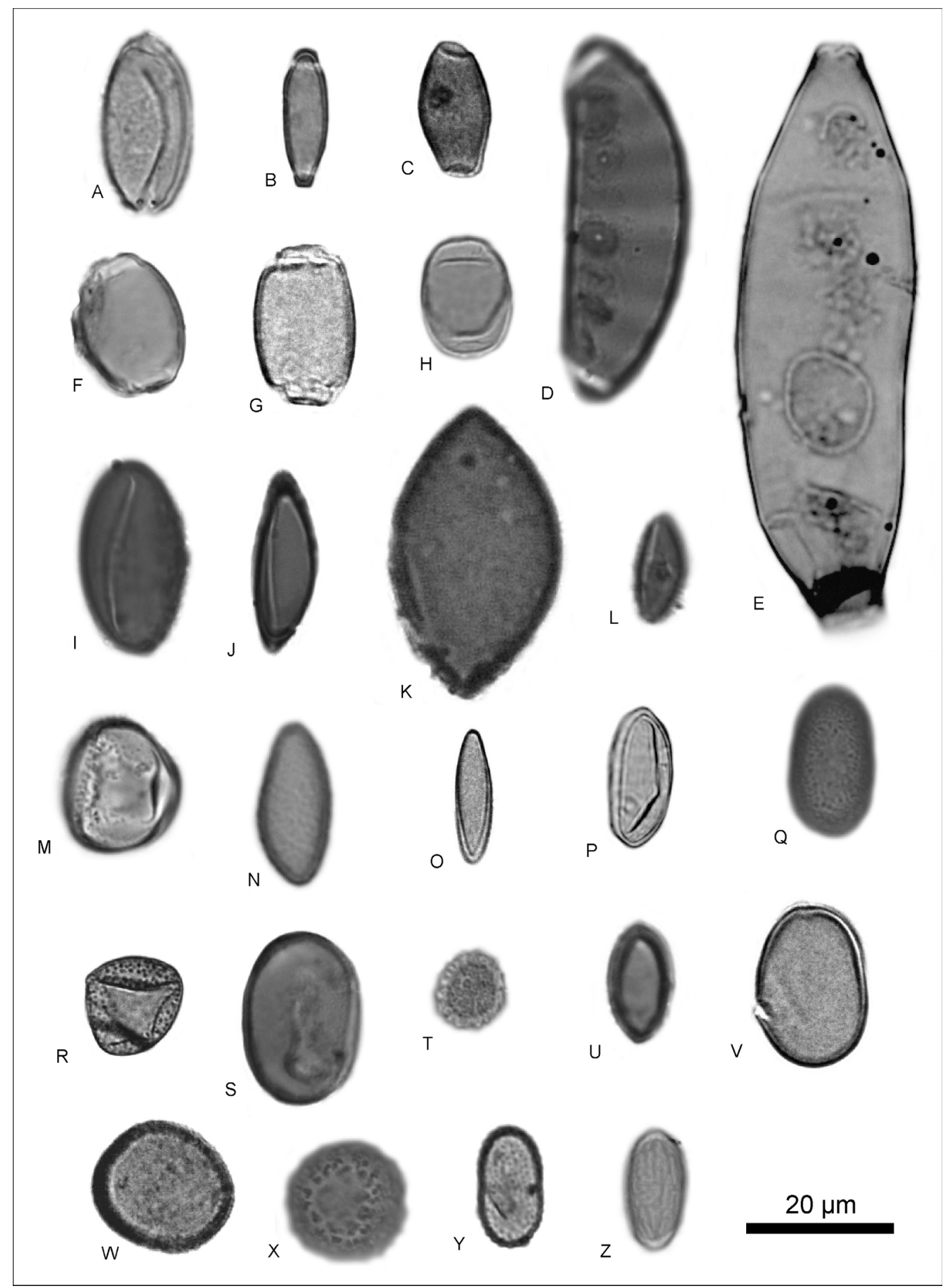

Figura 3. Fotomicrografias de esporos de fungos. A-E, Diporisporites; F-H, Foveodiporites; I-L, Hypoxylonites; M-Z, Inapertisporites.

Figure 3. Photomicrographs of fungal spores. 
terrestres (Diporisporites até 9,1\%), grãos de pólen de vegetação arbórea de floresta semidecidual (Actinostemon até $25 \%)$, de transição de floresta semidecidual para restinga (Allagoptera até $50 \%$ e Anacardiaceae até $25 \%$ ), pteridófitas (Cyathea até 100\%), arbóreas (Ouratea até 50\%) e herbáceas (Asteraceae-Eupatorieae até $50 \%$ ), de restinga e vegetação aquática (Cyperaceae até 9,1\%), presença exclusiva de
Podocarpus (atinge 100\% na amostra $358 \mathrm{~cm}$ ) e de vegetação herbácea terrícola de restinga (Cyathea até 50\%). Este nível é caracterizado pela ausência dos esporos e frutificações de fungos no topo da seção (Figura 2) e a deposição de sedimentos areno-argilosos, juntamente com alto percentual de Reduviasporonites, indicam uma influência marinha antes de 7.880 anos cal AP.

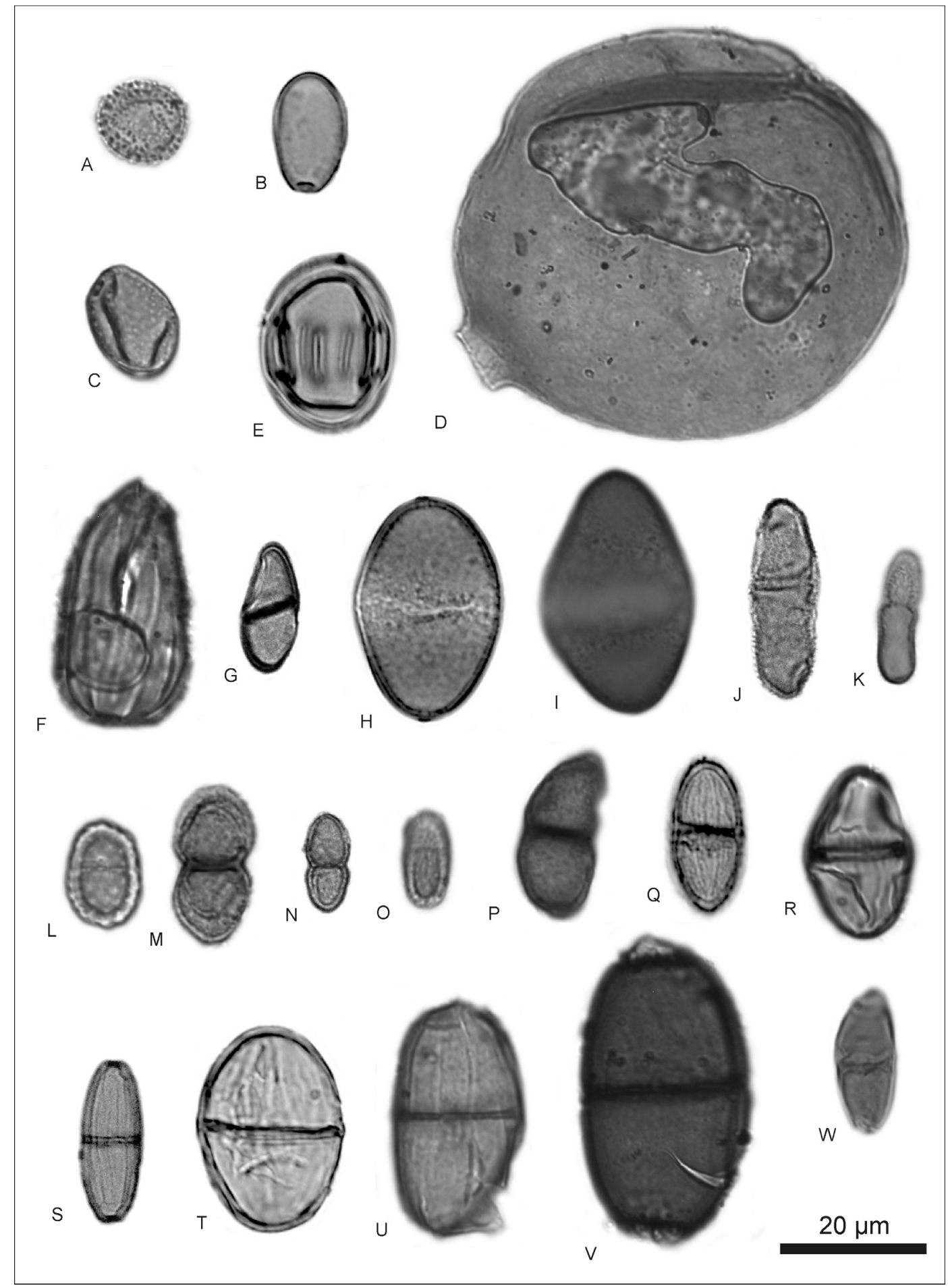

Figura 4. Fotomicrografias de esporos de fungos. A, Inapertisporites; B-D, Lacrimasporonites; E, Palaeoamphisphaerella; F, Striadisporites; G-P, Dicellaesporites; Q-U, Fusiformisporites; V-W, Dyadosporites.

Figure 4. Photomicrographs of fungal spores. 
Intervalo IB (349-30 cm). Nesta fase registraram-se esporos de fungos terrestres (2-50\%: Inapertisporites $28 \%$, Dictyosporites até 19,1\%, Lacrimasporonites até $7.8 \%$, Dyadosporites até 5,5\%, Pluricellaesporites até 5,3\% e Frasnacritetrus até 2,2\%), de ambientes costeiros/alagados (Hypoxylonites até 38,3\%, Dicellaesporites até 25,2\% e
Multicellaesporites até 13\%) e marinhos (0-73\%: Reduviasporonites até 6,2\%), elementos arbóreos de floresta semidecidual (Astronium até 11,6\%), da transição entre floresta semidecidual para restinga (Myrtaceae até 27,8\%, Sebastiania até 9,4\%, Alchornea até 7,3\%, Trema até 6,3\%, Allagoptera até $5,6 \%$ ), vegetação de restinga (Trichilia até

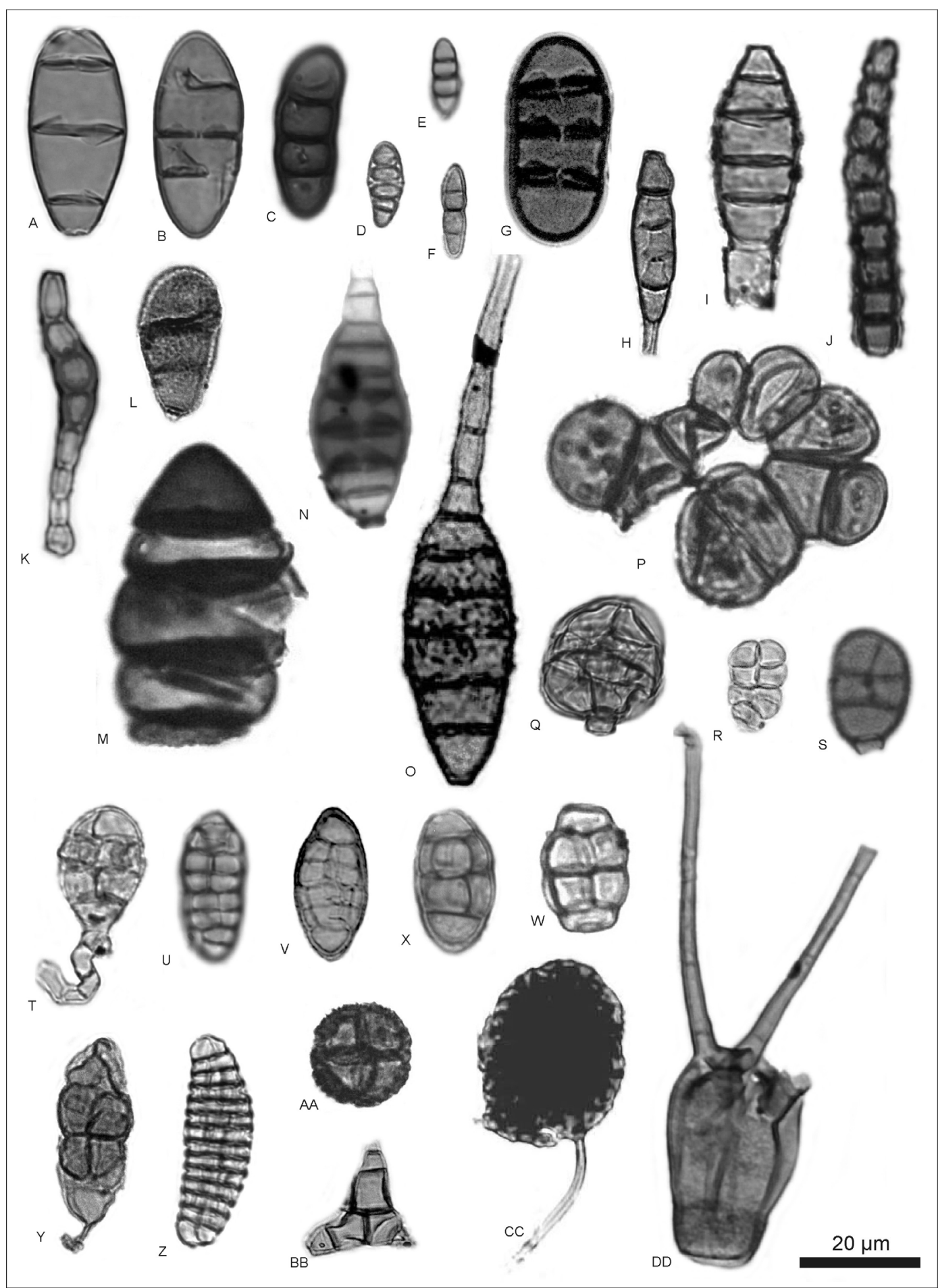

Figura 5. Fotomicrografias de esporos e frutificações de fungos. A, Diporicellaesporites; B-G, Multicellaesporites; H-M, Pluricellaesporites; N-O, Quilonia; P, Reduviasporonites; Q-T, Staphlosporonites; U-Z, Dictyosporites; AA, Spegazzinites; BB, Triporicellaesporites; CC, Callimothallus; DD, Frasnacritetrus.

Figure 5. Photomicrographs of fungal spores and frutifications. 
14,4\%, Rapanea até 14,3\%, Blutaparon até 6,2\%, Pouteria até 5,7\%, Maytenus até 5,3\%), manguezal (Avicennia até 2,6\%, Combretaceae-Melastomataceae até 2,4\%, Laguncularia até 2\%), pteridófitas de áreas brejosas e/ou alagáveis (Azolla até 42,7\%, Acrostichum até 5,6\%, Blechnum até 3,8\% e Polypodium até 3,8\%), aquáticas (Ruppia até 14,3\% e Cyperaceae até 11,2\%) e herbáceas de beira de lagoas e áreas abertas (Chenopodium até 20,8\% e Poaceae até 19,6\%). Foram registrados baixos percentuais de Botryococcus (até $0,3 \%$ ) e de elementos marinhos (dinocistos até $1,6 \%$, palinoforaminíferos até $0,7 \%$ e ovos de copépodes até $0,2 \%$ ). Os palinomorfos de ambiente lacustre (Azolla, Sphagnum e Anthoceros), de vegetação arbórea de morros litorâneos (Astronium) e da transição entre floresta semidecidual e restinga (Myrtaceae, Sebastiania, Alchornea, Trema, Allagoptera, Trichilia e Rapanea) e Ruppia indicam que a paleolaguna teve pulsos de clima mais seco e maior deposição de sedimentos carbonáticos em torno de 5.590 anos cal AP. Outro período caracterizado como mais seco ocorreu entre 5.590 e 4.410 anos cal AP, quando houve diminuição dos elementos aquáticos e fungos em detrimento de elementos da mata seca de encosta, representada por elementos arbóreos de floresta semidecidual (Figura 2). Houve registro de influência marinha restrita neste intervalo, entre os níveis $329-320 \mathrm{~cm}$ e $289-260 \mathrm{~cm}$, indicada pela presença dos palinomorfos marinhos e Reduviasporonites.

Intervalo IC (30-0 $\mathbf{~ c m})$. Este intervalo apresenta esporos de fungos terrestres (Diporisporites até 9,7\%) e de ambientes costeiros e alagados (Hypoxylonites até $46,5 \%$ e Multicellaesporites até 6\%), vegetação arbórea de floresta semidecidual (Astronium até 8,9\%), da transição entre floresta semidecidual e restinga (Myrtaceae até 15,5\%, Trema até $8,3 \%$, Sebastiania até 6,2\%, Allagoptera até 6,1\%), restinga (Schinus até 10,4\%, Pouteria até 5,5\%), manguezal (Combretaceae-Melastomataceae até 1,2\%), pteridófitas de áreas brejosas e/ou alagáveis (Salvinia até 12,3\%, Blechnum até $4,7 \%$ ), vegetação aquática (Typha até 54,4\%, Cyperaceae até $9,6 \%$ e Ruppia até $7,1 \%$ ), herbáceas de beira de lagoas e áreas abertas (Poaceae até 40,3\%, Asteraceae-Tribo Eupatorieae até $10,1 \%$, Borreria até 7,8\%) e algas dulcícolas (Botryococcus até 29,1\%). Dentre os palinomorfos marinhos, somente os dinocistos (até $0,4 \%$ ) foram registrados. A vegetação pioneira (Trema), elementos de restinga aberta (Myrtaceae, Pouteria, Schinus, Borreria e Asteraceae-Tribo Eupatorieae) e a vegetação aquática e herbácea de áreas pantanosas (Cyperaceae, Typha e Blechnum) atestam a presença de áreas recém-colonizadas no entorno da lagoa, por volta de 1.020 anos cal AP. Os esporos de fungos Hypoxylonites e Diporisporites indicam ambiente mais úmido. A ausência de deposição carbonática e a maior contribuição de sedimentos argilosos com alto teor de matéria orgânica indicam que a paleolaguna sofreu confinamento até se configurar como corpo aquoso fechado desde 4.410 anos cal AP até ca. 90 anos cal AP (Figura 2).

\section{CONSIDERAÇÕES FINAIS}

Os esporos e frutificações de fungos holocênicos descritos neste trabalho foram comparados aos atuais, com os quais possuem semelhanças morfológicas. A interpretação de frequências relativas dos esporos e frutificações de fungos e de palinomorfos de diversas origens - floresta semidecidual, manguezal, aquáticas, herbáceas, pteridofíticas e marinhas identificados no testemunho RJ 92-5, possibilitaram fazer inferências sobre as mudanças paleoambientais da porção leste da península de Armação dos Búzios. A associação palinológica permitiu distinguir ao longo do testemunho três fases paleoambientais: uma fase de influência marinha antes de 7.880 anos cal AP, correspondente ao Intervalo IA, uma fase lagunar entre 7.880 e 1.020 anos cal AP (Intervalo IB) e uma fase lacustre entre 1.020 e 90 anos cal AP (Intervalo IC).

\section{AGRADECIMENTOS}

Os autores agradecem a J.-P. Ybert, R. Scheel-Ybert e L. Martin, pela coleta e processamento do testemunho analisado; a M. Toledo, pelas discussões palinológicas; a L. Morato, pela confecção das estampas dos microfungos; a Simone N. Brandão pelas sugestões de formatação do texto e das figuras e ao Conselho Nacional de Desenvolvimento Científico e Tecnológico-CNPq, pelo apoio financeiro (proc. 141161/2007-8).

\section{REFERÊNCIAS}

Carvalho, M.A. 1996. Estudo paleoecológico e paleoclimático, com base em palinologia, aplicado em sedimentos pleistocênicos e pliocênicos da bacia da Foz do Amazonas. Programa de Pósgraduação em Geologia, Universidade Federal do Rio de Janeiro, Dissertação de Mestrado, 146 p.

Carvalho, M.A. 2003. Paleoecological and paleoclimatic studies based on palynology of Pliocene and Pleistocene sediments from the Foz do Amazonas Basin, Brazil. Neues Jahbuch für Stratigrafie und Paläontologie, 229(1):1-18.

Elsik, W.C. 1976. Microscopy fungal remains and Cenozoic palynostratigraphy. Geoscience and Man, 15:115-120.

Elsik, W.C. 1996. Fungi. In: J. Jansonius \& D.C. McGregor (eds.) Palynology principles and applications. American Association of Stratigraphic Palynologists Foundation, Publishers Press, p. 293-306.

Ferreira, E.P.; Carvalho, M.A. \& Viviers, M.C. 2005. Palinologia (Fungos) da Formação Calumbi, Paleoceno da Bacia de Sergipe, Brasil. Arquivos do Museu Nacional, 63(3):395-410.

Freitas, A.G. 2005. Reconstrução paleoclimática com base na análise de palinomorfos continentais em sedimentos pleistocênicosholocênicos do talude continental brasileiro de bacia de Campos, RJ. Programa de Pós-graduação em Geologia, Universidade Federal do Rio de Janeiro, Dissertação de Mestrado, 126 p.

Hammer, O; Harper, D.A.T. \& Ryan, P.D. 2001. Past: Paleontological Statistics Software Package for Education and Data Analysis. Palaeontologia Electronica, 4(1):4-9.

Jansonius, J. \& Kalgutkar, R.M. 2000. Redescription of some fungal spores. Palynology, 24:37-47. doi:10.1080/01916122.2000.9989536

Jarzen, N. \& Elsik, W.C. 1986. Fungal palynomorphs recovered from Recent river deposits, Luangwa Valley, Zambia. Palynology, 10:35-60. doi:10.1080/01916122.1986.9989302

Juggins, S. 2003. C2 User Guide: Software for Ecological and Palaeoecological Data Analysis and Visualization, version 1.5., Newcastle, University of Newcastle, 73 p.

Kalgutkar, R.M. \& Jansonius, J. 2000. Synopsis of fossil fungal 
spores, mycelia and frutifications. Dallas, American Association of Stratigraphy Palynologists Fundation, 423 p. (Contributions Series 39).

Kalgutkar, R.M. \& McIntyre, D.J. 1991. Helicosporous fungi and Early Eocene pollen, Eureka Sound Group, Axel Heiberg Island, Northwest Territories. Canadian Journal of Earth Sciences, 28:364-371.

Kalgutkar, R.M. \& Sigler, L. 1995. Some fossil fungal form-taxa from the Maastrichtian and Palaeogene ages. Mycological Research, 99:513-522. doi:10.1016/S0953-7562(09)80706-5

Lange, R.T. \& Smith, P.H. 1971. The Maslin Bay flora, South Australia 3. Dispersed fungal spores. Neues Jahrbuch für Geologie und Paläontologie, 11:663-681.

Pirozynski, K.A.; Jarzen, D.M.; Carter, A. \& Day, R.G. 1988. Palynology and mycology of organic clay balls accompanying mastodon bones - New Brunswick, Canada. Grana, 27:123139. doi:10.1080/00173138809432838

Ramanujam, C.G.K. \& Rao, K.P. 1978. Fungal spores from the Neogene strata of Kerala in South India. In: INTERNATIONAL PALYNOLOGICAL CONFERENCE, 4, 1976-77. Proceedings, Lucknow, v. 1, p. 291-304.

Ramanujam, C.G.K. \& Srisailam, K. 1980. Fossil fungal spores from the Neogene beds around Cannanore in Kerala State. The Botanique, 9:119-133.

Saccardo, P.A. (1882-1931). Sylloge fungorum omnium hucusque cognitorum, 25 vols.

Stuiver, M. \& Reimer, P.J. 1993. Extended ${ }^{14} \mathrm{C}$ data base and revised CALIB $3.0{ }^{14} \mathrm{C}$ age calibration program. Radiocarbon, 35:215-230.
Van Geel, B. 1978. A palaeoecological study of Holocene peat bog sections in Germany and the Netherlands. Review of Palaeobotany and Palynology, 25:1-120. doi:10.1016/00346667(78)90040-4

Van Geel, B. \& Andersen, S.T. 1988. Fossil ascospores of the parasitic fungus Ustulina deusta in Emnian deposits in Denmark. Review of Palaeobotany and Palynology, 56:89-93. doi:10.1016/0034-6667(88)90076-0

Van Geel, B.; Aptroot, A. \& Mauquoy, D. 2006. Sub-fossil evidence for fungal hyperparasitism (Isthmospora spinosa on Meliola ellisii, on Calluna vulgaris) in a Holocene intermediate ombrotrophic bog in northern-England. Review of Palaeobotany and Palynology, 141(1-2):121-126. doi:10.1016/j.revpalbo.2005.12.004

Van Geel, B.; Buurman, J.; Brinkkemper, O.; Schelvis, J.; Aptroot, A.; Van Reenen, G. \& Hakbijl, T. 2003. Environmental reconstruction of a Roman Period settlement site in Uitgeest (The Netherlands), with special reference to coprophilous fungi. Journal of Archaeological Sciences, 30:873-883. doi:10.1016/ S0305-4403(02)00265-0

Wolf, F.A. 1967. Fungus spores in East African lake sediments.V. Mycologia, 59:397-404.

Ybert, J.P.; Salgado-Labouriau, M.L.; Barth, O.M.; Lorscheitter, M.L.; Barros, M.A.; Chaves, S.A.M.; Luz, C.F.P.; Ribeiro, M.; Scheel, R. \& Vicentini, K.R.F. 1992. Sugestão para padronização da metodologia empregada para estudos palinológicos do Quaternário. Revista do Instituto Geológico, 13(2):47-49.

Received in December, 2010; accepted in April, 2011. 